\title{
The Acoustic Water Column Profiler: a Tool for Long-term Monitoring of Zooplankton Populations
}

\author{
D. D. Lemon, ASL \\ Environmental Sciences Inc., \\ 1986 Mills Rd., Sidney, BC \\ V8L 5 Y3 Canada
}

\author{
J. F. R. Gower and M. V. \\ Trevorrow*, Institute of \\ Ocean Sciences, $9860 \mathrm{~W}$. \\ Saanich Rd., Sidney, BC \\ V8L 3S1 Canada
}

\author{
M. R. Clarke, ASL \\ Environmental Sciences Inc., \\ 1986 Mills Rd., Sidney, BC \\ V8L 5 Y3 Canada
}

\begin{abstract}
Measuring acoustic backscatter in the water column is a low-cost, reliable method for examining the longterm behaviour and distribution of zooplankton populations. Backscatter at acoustic frequencies above $20 \mathrm{kHz}$ is useful for profiling those quantities, which, when tracked over long periods of time, can provide a valuable contribution to understanding and monitoring the state of marine ecosystems. The Water Column Profiler ${ }^{\mathrm{TM}}$ is a self-contained echosounder, designed for long-term, autonomous operation. The instrument can be used in either downward-looking mode, from a moored surface buoy, or in upward-looking mode from a submerged mooring. The instrument has selectable parameters for pulse length and sampling interval. The data are recorded in digital form, and averaging in both time and range is available. On-board storage of up to 64 Mbytes of non-volatile Flash RAM allows operation for periods up to 6 months in length for $150 \mathrm{~m}$ water depth sampled at $1 \mathrm{~m}$ intervals every minute. Interfacing to a real-time data link is possible for buoy-mounted installations.
\end{abstract}

A $200 \mathrm{kHz}$ Water Column Profiler ${ }^{\mathrm{TM}}$ has been operating on a moored buoy in Saanich Inlet, British Columbia, since September 1999. In June, 2000, a $50 \mathrm{kHz}$ unit was added. Time series of acoustic backscatter at both frequencies many months long have been collected, showing the evolution of the behaviour and abundance of the dominant species of zooplankton (Euphausiids and Amphipods) in the Inlet over time scales from diurnal to seasonal. Examples of these data are presented and discussed, comparing the results at the two frequencies and the implications for acoustically discriminating size with a multi-frequency instrument.

\section{INTRODUCTION}

High-frequency echo sounders have been used for some time as a qualitative means to measure the presence of zooplankton in the water column. In most cases, these echo sounders have been vessel mounted and used to provide short-term records. The Acoustic Water Column Profiler ${ }^{\mathrm{TM}}$ is a self-contained echo sounder, designed for long-term, autonomous operation either submerged, or mounted on a

*Now at Defence Research Establishment Atlantic, P.O. Box 1012, Dartmouth, NS B2Y 3Z7, Canada. surface buoy. The instrument is capable of recording durations of weeks or months, thus allowing long-term monitoring of some biological processes in the ocean. In particular, the abundance and behaviour of zooplankton can be monitored for extended periods, providing long time series covering the tidal, daily and seasonal changes. The Profiler has been developed from ASL's existing Ice and Wave Profilers ${ }^{\mathrm{TM}}$, which in turn were developed from earlier Ice Profiling Sonars developed at the Institute of Ocean Sciences. In its present form, the Profiler is a singlefrequency instrument, which provides a signal proportional to the volume back-scattering strength in the water as a function of range from the instrument. With a single acoustic frequency, it is not possible to distinguish between different species and sizes of zooplankton; the data provide only a measure of the integrated volume backscattering strength. However, in environments where the populations are dominated by a single species, or where there are only a few species whose behaviour differs enough to allow them to be identified separately, the single-frequency instrument can provide useful information.

As part of IOS's MEOS (Marine Ecosystem Observatory) program, a $200 \mathrm{kHz}$ Profiler was mounted on a buoy moored in Saanich Inlet, BC beginning in September, 1999. The inlet has a relatively well understood zooplankton community, and therefore was chosen as suitable site to test a single-frequency instrument.

\section{INSTRUMENT DESCRIPTION}

The Water Column Profiler ${ }^{\mathrm{TM}}$ is available in 50, 200 or $420 \mathrm{kHz}$ versions, all of which can be configured for underwater (Fig. 1) or surface (e.g. for buoy mounting, Fig. 2) installations. In each case, the instrument records internally; the subsurface unit is entirely self-contained, while the surface version requires an external battery for power. In the buoy-mounted version, a serial output port is available for real-time data transmission over a radio or other link. 


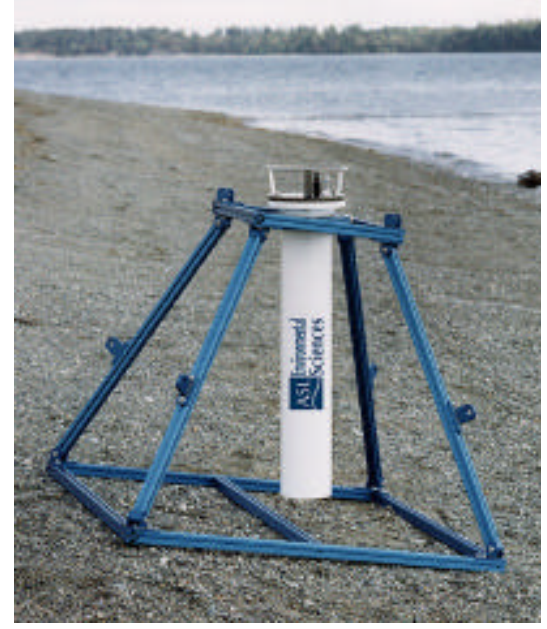

Fig. 1. Underwater version of the Profiler in a bottom frame for upward-looking application.

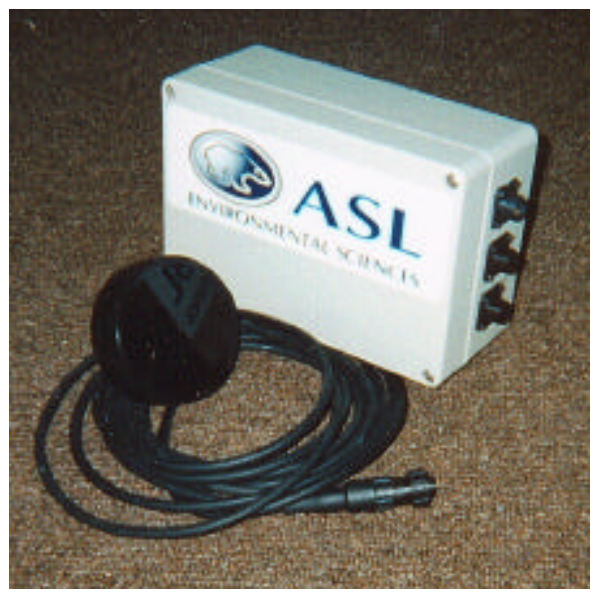

Fig. 2. Module for use in surface buoy configuration.

The transducer beamwidths available range from $2^{\circ}$ at $420 \mathrm{kHz}$ to $15^{\circ}$ at $50 \mathrm{KHz}$. The transmitted pulse width is variable and can be specified by the user ( 4 to $1020 \mu \mathrm{sec}$ ), and the system is equipped with up to $80 \mathrm{~dB}$ of timevariable gain following a $20 \log \mathrm{R}+2 \mathrm{aR}$ form. There is up to 64 Mbytes of solid state data storage in the instrument. The operation cycle is also user-specified, including wake and burst sampling at intervals from 1 minute to 72 hours, with the number of pings per burst specifiable. The ping rate is fixed at $1 \mathrm{~Hz}$. Samples can be averaged in both time and range for storage; the bin size for range averaging can be selected between 0.25 and $4 \mathrm{~m}$, up to a maximum range for recording of $200 \mathrm{~m}$.

\section{SAANICH INLET MEASUREMENTS}

\section{A. Data Collection}

A single Water Column Profiler ${ }^{\mathrm{TM}}$ system operating at 200 $\mathrm{kHz}$ was mounted looking downwards from the MEOS buoy (see Fig. 3) in Saanich Inlet, British Columbia, beginning in September, 1999. The $200 \mathrm{kHz}$ transducer (ITC model $6716,8^{\circ}$ beam-width) was mounted on the underside of a $3-\mathrm{m}$ discus buoy, oriented $15^{\circ}$ outwards to avoid backscatter from the buoy mooring chain. The water depth was nominally $60 \mathrm{~m}$, with tidal variations approximately 1 to $1.5 \mathrm{~m}$. This instrument was set to continuously record 5 ping averages ( $1 \mathrm{~s}$ per ping) of acoustic backscatter at $60 \mathrm{~s}$ intervals. A $305 \mu$ s transmit pulse was used, implying a $23 \mathrm{~cm}$ range resolution, with the waveform-detected amplitude sampled with 8-bit A/D resolution at $23.3 \mathrm{kHz}$, then averaged into $50 \mathrm{~cm}$ range bins. The total insonified volume for this $8^{\circ}$ beam increased with range, reaching maximum values of approximately $12 \mathrm{~m}^{3}$ near the seabed at $62 \mathrm{~m}$ range. Data was recorded internally on non-volatile Flash-RAM. This instrument was operated with minimal interruptions starting Sept. $10^{\text {th }}, 1999$ and was operated at this site until January, 2001. Every 4 to 24 days the instrument was stopped for a short period $(<1$ hour $)$ to retrieve the data.

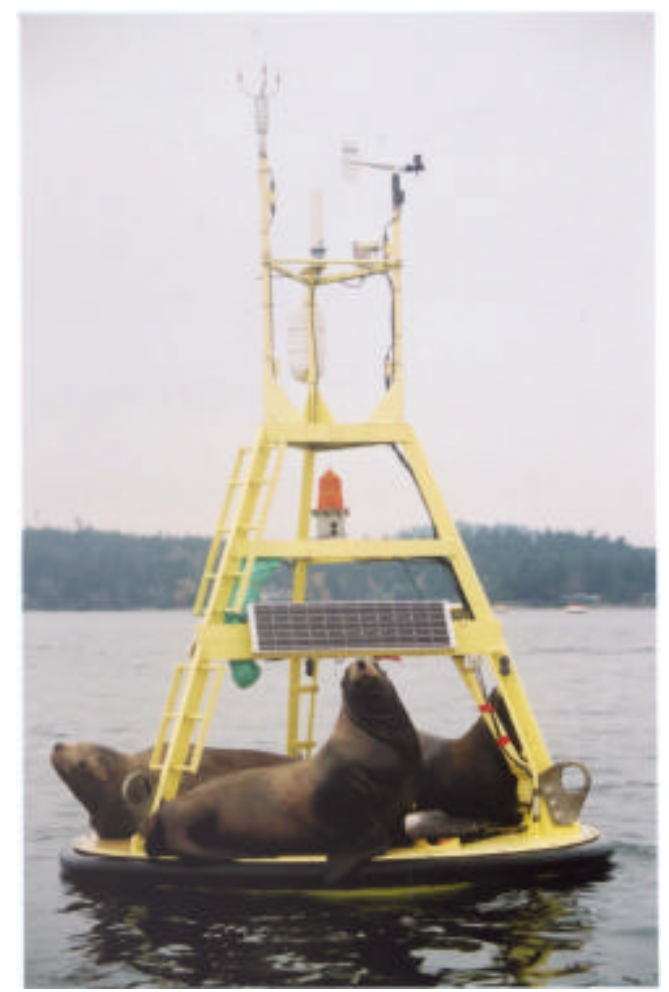

Fig. 3. MEOS buoy in Saanich Inlet.

In order to assess the feasibility of multi-frequency measurements, a second Profiler operating at $50 \mathrm{kHz}$ was built, tested, and acoustically calibrated. This was operated with the same sampling parameters alongside the $200 \mathrm{kHz}$ Profiler in April and May 2000. Fig. 4 shows a schematic diagram of the instrument mounting on the buoy. At this time efforts were made to measure the beam-patterns, timevarying gain responses, and the on-axis acoustic calibration coefficients for both sounders. In January, 2001, the MEOS 
buoy was moved to deeper water in Saanich Inlet, and the $50 \mathrm{kHz}$ transducer was removed for a planned replacement. Difficulties encountered with the replacement unit have meant that no simultaneous data at both frequencies have yet been obtained from the deeper site.

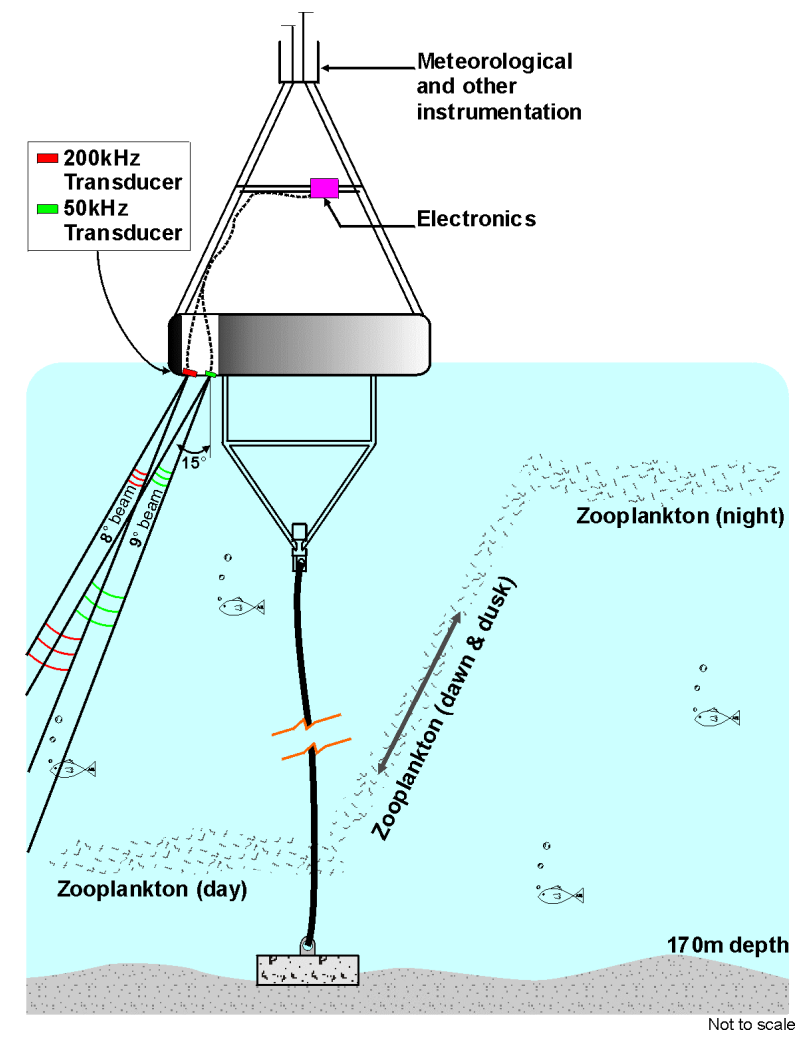

Fig. 4. Sketch of 50 and $200 \mathrm{kHz}$ Profilers mounted on the MEOS buoy (after moving to deeper water in January 2001).

\section{B. Calibration}

The transducer beam-patterns were measured with a high-resolution rotating mounting system and reference hydrophone at an IOS calibration tank. The $200 \mathrm{kHz}$ transducer had a $-3 \mathrm{~dB}$ beam-width of $8.0^{\circ}$, with quite low side-lobes, whereas the $50 \mathrm{kHz}$ transducer had a slightly wider and asymmetric beam-pattern $\left(12.7^{\circ}\right.$ average) with larger side-lobes. The TVG curves within each Profiler are generated by analog electronics and roughly approximate a 20log[range] variation; however individual measurements for each system are required. The measurements were performed by inserting a constant signal into the receiver front-end, then recording and averaging over several pings the resulting output amplitude. Measurements at several different input signal levels were pieced together to cover both short and longer range TVG variations.

The on-axis intensity calibrations were performed using as reference the backscatter from 3 specially machined Tungsten-Carbide spheres (diameter 38.1, 40.0, and 43.5 $\mathrm{mm}$ ), and a $15.9 \mathrm{~mm}$ diameter steel sphere. The detailed calibration calculations are explained in [1]. One problem encountered was that with the high gain used for both systems, the echoes from the larger target spheres were clipped at the A/D converter, thus requiring measurements at ranges of 10 to $20 \mathrm{~m}$. This greatly exceeded the size of the IOS calibration tank, requiring measurements to be made from a boat in Saanich Inlet. However, owing to alignment difficulties from the boat with the narrow-beam $200 \mathrm{kHz}$ system, and the need to minimize $200 \mathrm{kHz}$ system down-time, the on-axis intensity coefficient for the $200 \mathrm{kHz}$ system was not properly measured. For the purposes of this report, an approximate calibration for the $200 \mathrm{kHz}$ system was extracted from comparisons of target strength for isolated fish targets simultaneously visible in both sounders. Since fish targets can be assumed to be roughly frequencyindependent scatterers at frequencies $>10 \mathrm{kHz}$, the target strength should be the same. Target strength comparisons were averaged over a number of fish occurrences to produce an approximate calibration coefficient for the 200 $\mathrm{kHz}$ sounder. This ad hoc estimate is no replacement for a proper calibration, but demonstrates what could be accomplished given correctly calibrated systems.

\section{Saanich Inlet Zooplankton Populations}

It is expected that the high-frequency scattering layers observed with the Profiler, and particularly those exhibiting diurnal migrations, are composed of crustacean zooplankton such as euphausiids, amphipods, and various shrimp. Reference [2] found that deeper (80 to $120 \mathrm{~m}$ ) daytime acoustic scattering layers in Saanich Inlet were dominated by euphausiids (largely E. pacifica), which are known to migrate to the surface at night. Reference [3] reported dense $\left(>1000\right.$ per $\left.\mathrm{m}^{3}\right)$ mid-water Euphausiid layers from both net trawl and submersible observations in Saanich Inlet and other B.C. coastal areas. The euphausiids are joined in their diurnal migrations by amphipods and larger shrimp, however these are generally found deeper or on the bottom during the day and migrate to the mid-water during night-time [3]. Other species of Pteropods, Chaetognaths, Ctenophores, and Cnidaria (jellyfish) also diurnally migrate from the surface through depths of $250 \mathrm{~m}$. However in the context of interpreting echo-sounding data these can be largely ignored due to their low abundance and small target strength (these are soft- or gelatinous-bodied animals).

The most abundant species in B.C. coastal waters are Copepods, with adults reaching up to $5 \mathrm{~mm}$ in length. Neocalanus plumchrus appears to be the most common species. These species generally do not migrate on a daily basis, but rather they each have a strong seasonal growth and migration cycle. For example, young of N. plumchrus feeding on the spring bloom of phytoplankton grow rapidly in size and population in mid- and epi-pelagic zones (surface to $100 \mathrm{~m}$ ) in the March through June period, then the adults dive to deep waters $(>300 \mathrm{~m})$ for the remainder of the year. Other smaller copepod species also exhibit seasonal migration cycles, generally peaking after the descent of $N$. plumchrus in June. Summer and fall near- 
surface blooms of $C$. marshallae, $C$. pacificus, Pseudocalanus, and M. pacifica are common [4].

\section{Backscatter Data}

The long time-series of $200 \mathrm{kHz}$ acoustic data covers a wide range of ecological and meteorological conditions. The most obvious features of the sounder data are demonstrated by the 24-hour intensity vs. depth and time display in Fig. 5. In this figure and henceforth the axis labelled depth is actually slant range along the beam oriented $15^{\circ}$ away from nadir. Echoes from the buoy mooring gear dominate the first $3.5 \mathrm{~m}$ from the sounder. The faint line near $6 \mathrm{~m}$ depth is due to echoes from a water intake pipe. The seabed echo is the intense feature near 62 $\mathrm{m}$ depth, with a dark line indicating the seabed interface detected using a simple threshold technique. Variations in range to seabed due to tides are clearly visible.

A ubiquitous feature of this data is the zooplankton diurnal migration cycle. In Fig. 5 there is a dramatic rise of zooplankton from the seabed near 1800h (360 minutes after the start), and a similarly strong downwards migration near 0900h. During the night the zooplankton seem to divide into two groups: a surface-oriented population forming transient swarms up to $35 \mathrm{~m}$ deep, and a deeper population concentrated within approximately $10 \mathrm{~m}$ of the bottom. From this depth-stratification it can be hypothesized that the near-surface population is dominantly Euphausiids and the deeper population is likely composed of Amphipods with some presence of Mysid and Decapod shrimp. Clearly,

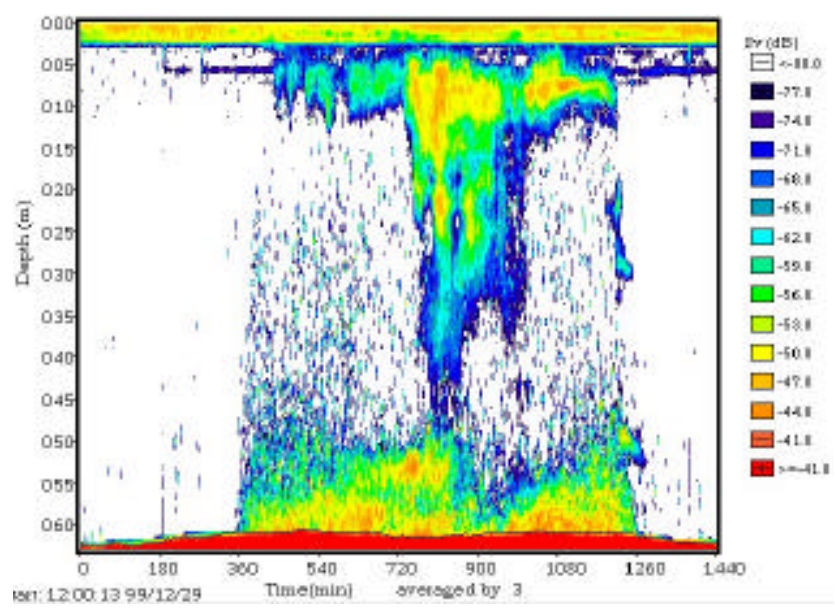

Fig. 5. $200 \mathrm{kHz}$ volume scatter strength vs. depth and time covering a 24-hour period starting 1200PST Dec. 29th, 1999.

some combination of net trawls and multi-frequency sounder analysis is necessary to resolve the species composition. The volume scattering strengths for both surface and bottom populations approach $-40 \mathrm{~dB}$. Given approximate euphausiid and amphipod target strengths near
$-75 \mathrm{~dB}$ (re $1 \mathrm{~m}^{2}$ ), these clouds suggest abundance up to 3200 per $\mathrm{m}^{3}$, which is not unreasonable for the euphausiids but possibly too high for the amphipods. Also, in Figure 5 note that the water column is essentially empty during daylight hours, which was typical of the mid-winter conditions.

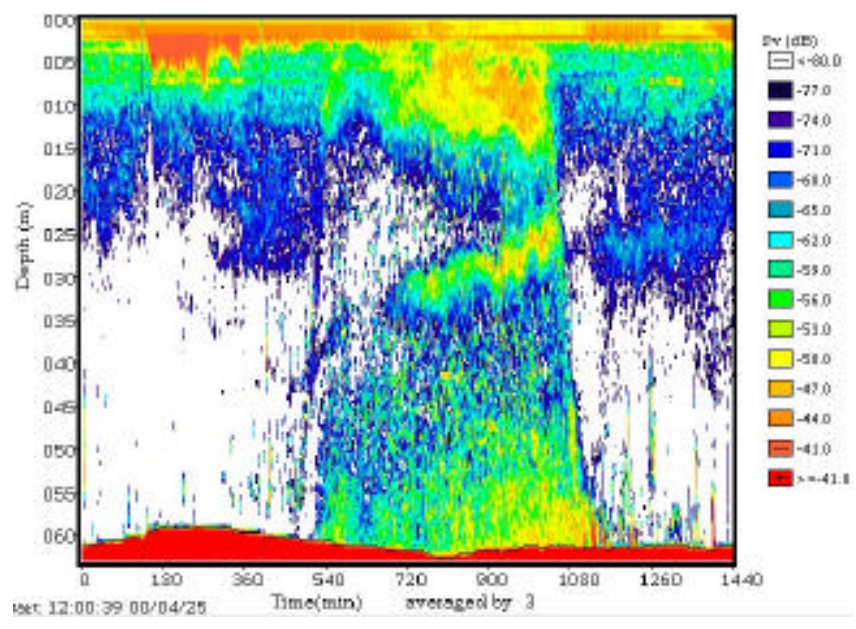

Fig. 6: $200 \mathrm{kHz}$ volume scatter strength vs. depth and time covering a 24-hour period starting 1200PDT April 25th, 2000.

Fig. 6 shows a similar 24-hour intensity vs. depth and time echogram taken near the end of April. There remains a similar nocturnal migration behaviour, now compressed between $2000 \mathrm{~h}$ and $0630 \mathrm{~h}$ by the shorter nights. Also, there is a significantly greater daytime scattering level in the upper $35 \mathrm{~m}$, which increases in strength towards the surface. Since this background population of zooplankton does not exhibit a nocturnal migration and has definitely increased through the spring months, it can hypothesized that it is due to copepods. Another feature of Fig. 6 is the presence of strong, surface-connected scattering plumes within the upper $5 \mathrm{~m}$, due to small air bubbles injected and mixed downwards by breaking wave activity. These were commonly observed during windy periods, and were presumably concentrated by wave action against the buoy. Finally, a common feature of the late-winter and springtime data during daytime hours are schools of small fish (size unknown), seen as isolated, short duration lines near the bottom. Small fish such as herring are well-known to form schools during the daytime, and presumably these fish disperse into the water column at night to forage on the zooplankton.

Fig. 7 shows an example of simultaneous backscatter at $50 \mathrm{kHz}$ and $200 \mathrm{kHz}$ observed on August 21, 2000. The plots shows the raw data counts for each frequency, not calibrated to scattering strength. The diurnal cycle of plankton migration is apparent in the record from both frequencies, as are other isolated targets likely corresponding to schools of small fish. 

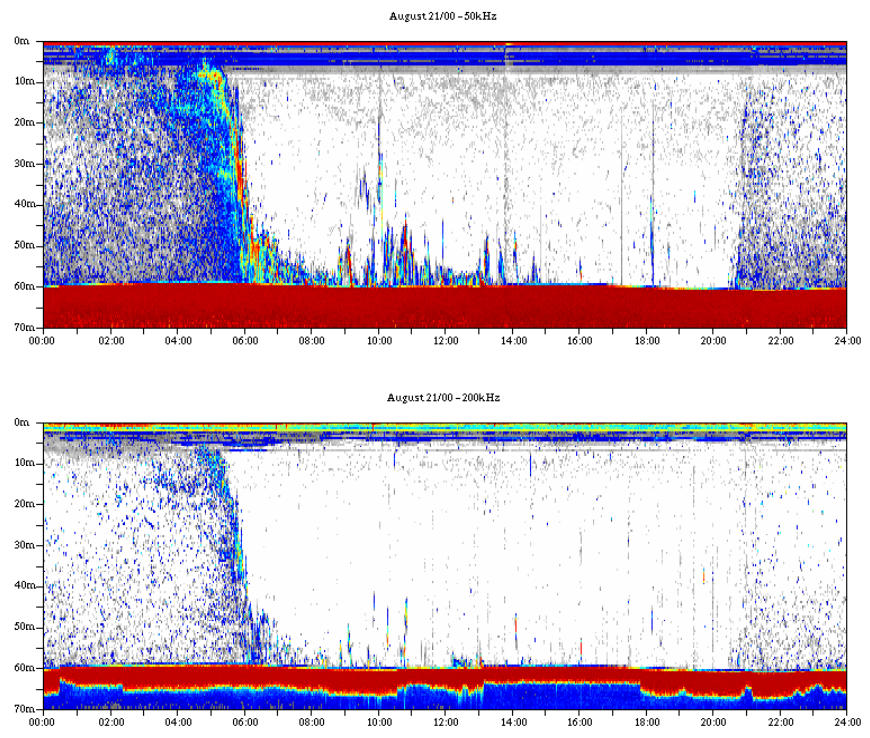

Fig. 7. Simultaneous $50 \mathrm{kHz}$ (upper panel) and $200 \mathrm{kHz}$ backscatter data for 24 hours on August 21, 2000.

After the MEOS buoy was moved to the deeper Saanich Inlet location in January, 2001, long-duration data series at depth became available. Fig. 8 shows an example covering six days in early June, 2001. The main scattering layer, which at the shallow site disappeared during daylight, can now clearly be seen near the bottom at approximately 150 $\mathrm{m}$.

\section{FURTHER DEVELOPMENT}

\section{A. Modelling Zooplankton Backscatter}

Modeling the acoustic backscatter from zooplankton is a difficult problem, particularly when one considers that the Profiler produces volumetric measurements averaged over different animal sizes, orientation, and species. The general acoustic modeling approach approximates the zooplankter as an idealized shape of fluid-like material having a small contrast in density and sound speed relative to seawater. Current literature has focused almost exclusively on euphausiids and copepods, with the usual modeling approximations being spherical or cylindrical using a characteristic radius and/or length (see [5] for a review). Purely empirical approaches are also employed, generally fitting a curve of the form $T S=\mathrm{A}+\mathrm{B} \cdot \log [$ frequency], where $T S$ is target strength $(=10 \cdot \log [$ back-scatter crosssection] and A, B are constants. In general the acoustic scattering can be divided into two regimes: 1) the Rayleigh regime at relatively low frequencies where the scattering cross-section increases as approximately the fourth-power of the acoustic wave-number $(k)$, and the higher-frequency geometric regime where there is a much weaker frequency dependence. The transition region between these regimes lies near $k$ radius $\approx 1$. In the Rayleigh regime the particular choice of scattering model is less important, so a spherical approximation is

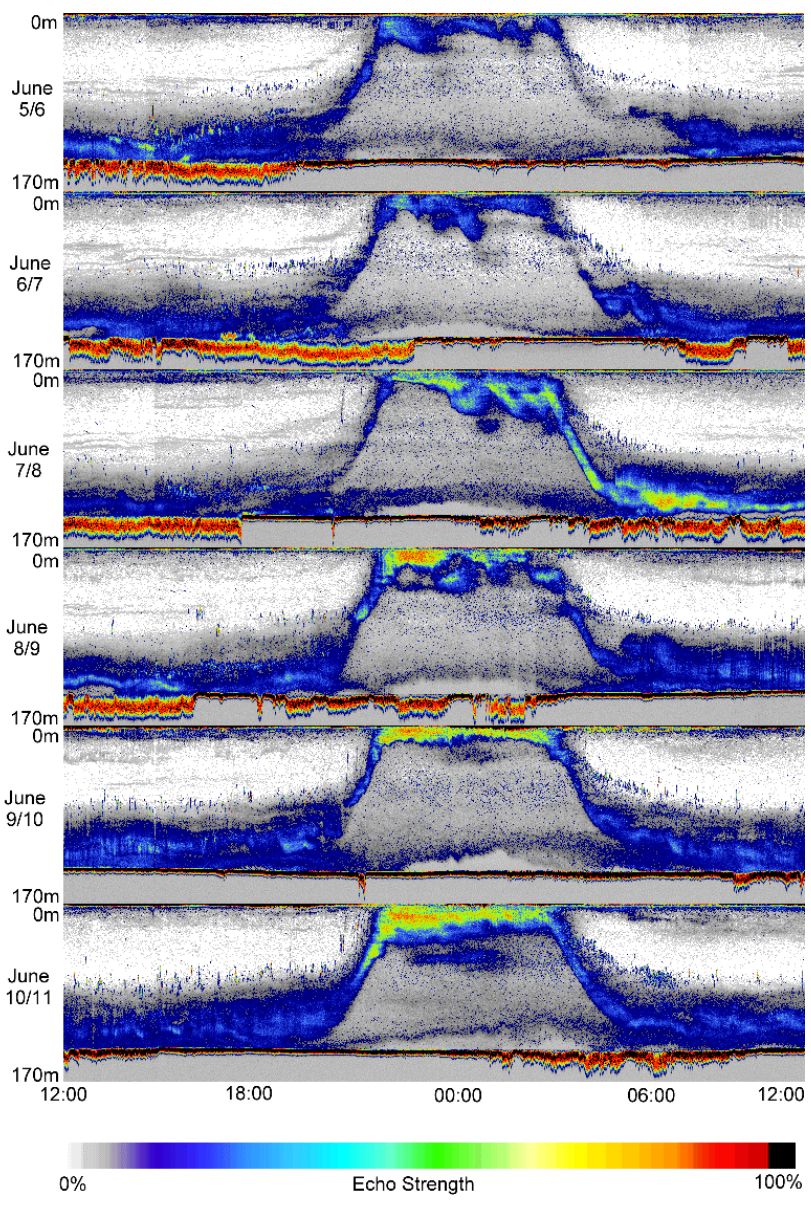

Fig. 8. Six-day sequence of $200 \mathrm{kHz}$ backscatter at the $170 \mathrm{~m}$ depth Saanich Inlet site, starting 1200 PDT, June 5, 2001.

usual. Through the transition region into the geometric regime, the choice of scattering model is more important as the effects of zooplankter elongation, curvature, and orientation become more significant. For example, [6] found that a cylindrical model for $9 \mathrm{~mm}$ long amphipods better fit the measured scattering strengths in the 50 to 200 $\mathrm{kHz}$ transition region. For the two Profiler frequencies used in this study, euphausiids lie in the transition region and copepods lie in the Rayleigh regime. Thus for both classes of zooplankton there are large differences in the scattering strengths between 50 and $200 \mathrm{kHz}$.

\section{B. Multi-frequency Measurement}

A numerical simulation of frequency-dependent backscatter from zooplankton, incorporating both the spherical and cylindrical scattering models was developed to assess the capability of a limited number of frequencies to distinguish mixed populations of zooplankton. Using population distributions typical of Saanich Inlet and the North Pacific more generally, with lengths between 4 and $25 \mathrm{~mm}$, the simulation program was capable of 
distinguishing up to 6 different size classes within that range, using a maximum of 6 frequencies between $50 \mathrm{kHz}$ and $800 \mathrm{k} \mathrm{Hz}$. If some of the characteristics of the population distribution are known, it is possible to reduce the number of frequencies. Operation at $50 \mathrm{kHz}$ and 200 $\mathrm{kHz}$ will continue at the Saanich Inlet buoy; some net collections have been made which will be assessed to verify the conclusions drawn from the backscatter data. Those results, together with the backscatter simulation will be used to guide the design of a multi-frequency version of the Water Column Profiler ${ }^{\mathrm{TM}}$.

\section{CONCLUSIONS}

The Acoustic Water Column Profiler $^{\mathrm{TM}}$ provides autonomous, long-term recording of acoustic backscatter from the water column. Extended measurements at a moored buoy have shown that such time series can provide valuable data concerning the behaviour and distribution of zooplankton populations on weekly, monthly and seasonal time scales. Such data can contribute greatly to understanding and monitoring marine ecosystems.

Multi-frequency measurements offer the possibility of separating the contributions to the backscatter signal from different zooplankton populations. The expansion of the Profiler to multi-frequency operation will be assessed using numerical simulations and dual frequency data to be collected at the Saanich Inlet monitoring buoy.

\section{Acknowledgements}

This work was partially funded by the Department of Fisheries and Oceans, Canada and by ASL Environmental Sciences. Within ASL, V. Bernard developed the numerical scattering simulation and $R$.Chave wrote the data retrieval software. J. Wallace of IOS maintained the instrument installation on the MEOS buoy.

\section{References}

[1] Vagle, S., K. Foote, M. Trevorrow, and D. Farmer, 1996. Absolute calibrations of monostatic echosounder systems for bubble counting, IEEE J. Oceanic Eng. 21(3): 298-305.

[2] Pieper, R., 1971. A study of the relationship between zooplankton and high-frequency scattering of underwater sound, Ph.D. dissertation, Univ. of British Columbia.

[3] Mackie, G., and C. Mills, 1983. Use of the Pisces IV submersible for zooplankton studies in coastal waters of British Columbia. Can. J. Fish. Aquat. Sci. 40: 763-776.

[4] Harrison, P., J. Fulton, F. Taylor, and T. Parsons, 1983. Review of the biological oceanography of the Strait of Georgia: pelagic environment, Can. J. Fish. Aquat. Sci. 40: 1064-1094.

[5] Stanton, T. K., and D. Chu, 2000. Review and recommendations for the modeling of acoustic scattering by fluid-like elongated zooplankton: euphausiids and copepods, ICES J. Mar. Sci. 57: 793807.

[6] Trevorrow, M., and Y. Tanaka, 1997. Acoustic and in situ measurements of freshwater amphipods (Jesogammarus annandalei) in Lake Biwa, Japan, Limnol. Oceanogr. 42(1): 121-13 